\title{
Energy Interconnection between Rock Mass Transportation and Destruction of Rear Axles Structural Sections of BelAZ Mining Dump Trucks
}

\author{
Ilya Kuznetsov ${ }^{1}$, Ivan Panachev ${ }^{1}$, Igor Zyryanov ${ }^{2}$, and Georgiy Shirokolobov ${ }^{1}$ \\ ${ }^{1}$ T.F. Gorbachev Kuzbass State Technical University, 650000, Kemerovo, 28 Vesennya st., Russian \\ Federation \\ ${ }^{2}$ Yakut research and design Institute of the diamond mining industry "Yakutniproalmaz", Republic of \\ Sakha (Yakutia), Mirny, Lenin street, 39, Russia
}

\begin{abstract}
The paper presents analytical formulae of the transportation energy of blasted rock mass depending on the route slopes. The figures are obtained for mining dump trucks with a carrying capacity of up to 55 tons, from 55 to 130 tons and from 130 to 320 tons. In addition, analytical formulae are presented for the total destructive energy of the structural section elements of dump trucks depending on the longitudinal slope of the route. The work uses the parameters of crack-like defects that are formed on the rear axle housing component of BelAZ heavy dump trucks. The energy dependences of the transportation and destruction processes for mining trucks of various carrying capacities are given. An energy joint diagram has also been constructed, which allows determining the maximum allowable values of the transportation energy of the rock mass and the destruction of the structural section elements for given route slopes.
\end{abstract}

\section{Introduction}

Rock mass transportation by heavy trucks according to the criterion of energy intensity can be divided into energy-consuming and energy-saving modes.

Energy-saving mode includes such stages as loading and unloading, waiting for loading, shift change, lunch break. At these stages, the dump truck does not move, the engine idles, and therefore, there is no significant energy consumption. The impact on energy intensity is provided only by the serviceability of the fuel system and engine. If these components of the dump truck are in good condition, energy costs are acceptable [1-3].

The main influence on the energy change during exploded rock mass transportation and the destruction of structural sections of mining dump trucks is in energy-consumption operating modes. These include the movement of the truck along straight technological roads, uphill and downhill, turnings and railway crossings. 
The largest energy amount of a loaded dump truck is spent on the uphill and downhill, when transporting rock mass. In these areas, mining technological and technical factors have an interconnected effect, which affects both durability and energy intensity [4-8].

Methods and means of probabilistic statistics were used in order to establish the relationship of energy-intensive processes of rock mass transportation and the destruction of structural sections elements of mining trucks to reduce mining equipment downtime, as well as labour and financial costs.

\section{Results and Discussion}

\subsection{Transportation energy of exploded rock mass by dump trucks}

The value of the specific energy consumption was adopted as a criterion for assessing the energy efficiency of transport systems in deep pits; it was determined by the formula

$$
P_{f}=\frac{g}{i} k_{\text {proc }} k_{s h} k_{m}
$$

where $\mathrm{P}_{f}$ is the specific energy consumption for transporting 1 ton of rock mass per $1 \mathrm{~m}, \mathrm{~g} . \mathrm{f}$ $/ \mathrm{t} \cdot \mathrm{m}$ (gram of standard fuel $/ \mathrm{t} \cdot \mathrm{m}$ ); $g$ - specific diesel fuel consumption of a mining truck, $\mathrm{g} / \mathrm{t} \cdot \mathrm{m} ; i$ - is the route slope, $\% ; k_{\text {proc }}$ - processing coefficient, taking into account the energy costs of obtaining diesel fuel from oil $\left(k_{\text {proc }}=1.18 \div 1.20\right) ; k_{\mathrm{d}}$ - coefficient taking into account energy costs for the extraction and transportation of fuel $\left(\mathrm{k}_{\mathrm{d}}=1.04 \div 1.10\right)$; $\mathrm{k}_{\mathrm{sh}}-\mathrm{co}$ efficient taking into account the difference in specific heat of combustion of diesel and standard fuel $\left(k_{\mathrm{sh}}=1.5\right)$.

The specific diesel fuel consumption of a mining truck was calculated from the formula

$$
g=\frac{Q}{m l}
$$

where $Q$ is the consumption of diesel fuel, $\mathrm{g} ; m$ is the mass of the transported cargo, $\mathrm{t} ; l$ is the transportation distance, $\mathrm{m}$.

The specific energy of transportation of the exploded rock mass by heavy dump trucks was determined as the specific work spent on transporting the rock mass

$$
A=P_{f}\left(k_{c}+1\right)\left(\frac{\omega_{0}}{i}+1\right),
$$

where $A$ is the specific work for the transportation of rock mass, $\mathrm{kJ} / \mathrm{t} \cdot \mathrm{m} ; k_{\mathrm{c}}$ is the coefficient of the truck container; $\omega_{0}$ - coefficient of resistance to movement of a loaded dump truck; $i$ is the route slope, $\%$.

Such components as the coefficient of resistance to movement of a loaded dump truck $\left(\omega \_0\right)$, the route slope (i), the specific energy costs for rock mass transportation (Rf) affect both the specific work characterizing the energy intensity and the value of the fracture energy of fracture-like defects in metal structures of dump truck.

In [4] the relationship between the specific energy consumption and the longitudinal slope of the route was established, when BelAZ mining dump trucks were divided into three groups by load capacity: 


$$
\begin{aligned}
\text { to } 55 t \rightarrow P_{f}^{55} & =0.0005 i^{2}+0.07 i+1.01 \\
\text { from } 55 t \text { to } 130 t & \rightarrow P_{f}^{130}=0.0004 i^{2}+0.04 i+2 ; \\
\text { from } 130 t \text { to } 320 t & \rightarrow P_{f}^{320}=0.00038 i^{2}+0.008 i+3 .
\end{aligned}
$$

Then, on the basis of (3) with the values of the coefficients $\left(k_{\mathrm{t}}=0.8, \omega_{0}=0.2\right)$ and formula (4), we obtain the dependence of the specific energy of rock mass transportation on the longitudinal slopes of the route (Fig. 1):

$$
\begin{gathered}
A^{55}=0.001 i^{2}+0.13 i+0.364 i^{-1}+1.84 \\
A^{130}=0.0007 i^{2}+0.07 i+0.7 i^{-1}+3.6 \\
A^{320}=0.00068 i^{2}+0.15 i+1.08 i^{-1}+5.4 .
\end{gathered}
$$

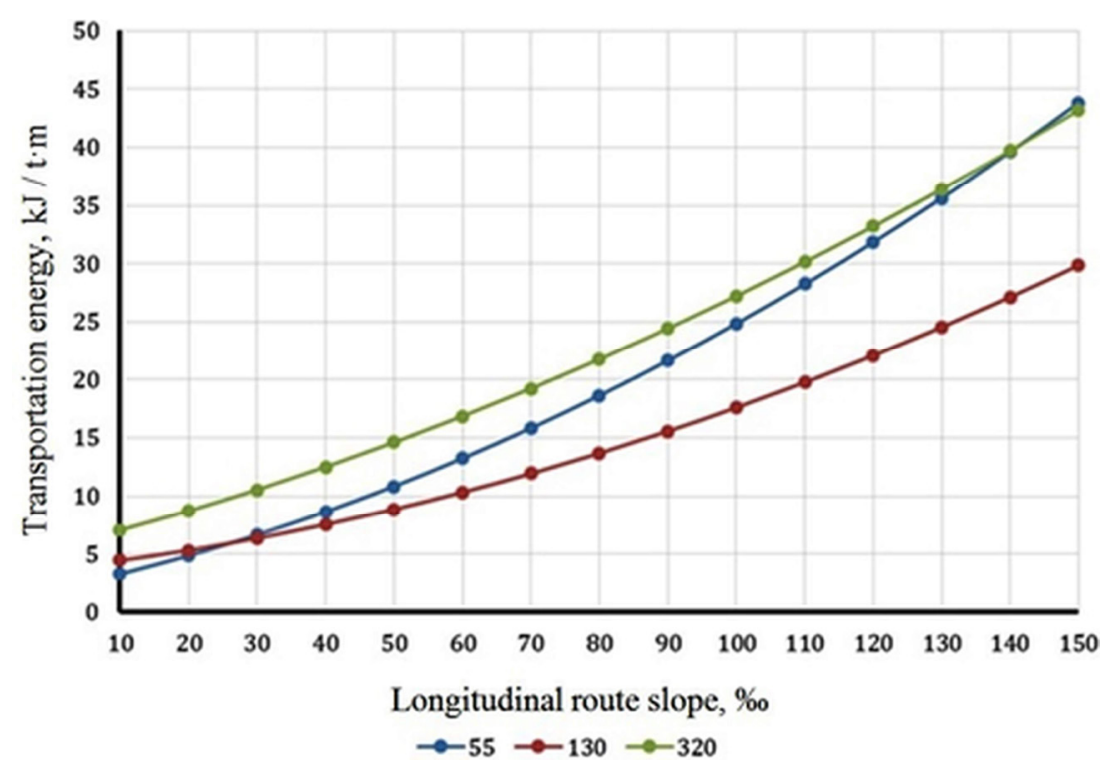

Fig. 1. Dependences of the specific transportation energy of mining trucks on the route slope.

\subsection{Destructive energy of rear axles metal structures of dump trucks when there are crack-like defects}

During mining trucks operation damages accumulate in their metal structures, leading to brittle rapture. The first studies in the field of brittle destruction formation were performed by A. Griffiths. According to A. Griffiths, the total energy destruction is calculated as [9$15]$

$$
\gamma=\frac{\pi l_{c} \sigma^{2}}{E}
$$

where $\gamma$ - is the total energy of destruction, $\mathrm{MJ} ; l_{\mathrm{c}}$ is the critical crack length, $\mathrm{m} ; \sigma-$ stresses in the metal structure, MPa; $E$ - first kind elasticity modulus, MPa.

According to the basics of probabilistic statistics, in equation (6) it is necessary to use the mathematical expectation of the amplitude of the stresses $\left(\mathrm{M}_{\sigma \mathrm{a}}\right)$ appearing in rear axle metal structures of a dump truck. 
It was found that $\mathrm{M}_{\sigma \mathrm{a}}$ depends on the longitudinal slopes of the route, taking into account the previously used division of mining dump trucks by load capacity:

$$
\begin{gathered}
M_{\sigma a}^{55}=0,024 i^{2}-1,07 i+39,1 \\
M_{\sigma a}^{130}=0,012 i^{2}-0,5 i+33,9 ; \\
M_{\sigma a}^{320}=0,006 i^{2}-0,23 i+32,7 .
\end{gathered}
$$

In this case, the elastic modulus of the first kind for steel $30 \mathrm{~L}$, from which the rear axles of BelAZ mining dump trucks are made, is taken to be $2.1 \times 10^{5} \mathrm{MPa}$. The formulae (7) are the following:

$$
\begin{gathered}
\gamma^{55}=1.5 \times 10^{-5} l_{c}\left(0,024 i^{2}-1,07 i+39,1\right) \\
\gamma^{130}=1.5 \times 10^{-5} l_{c}\left(0,012 i^{2}-0,5 i+33,9\right) \\
\gamma^{320}=1.5 \times 10^{-5} l_{c}\left(0,006 i^{2}-0,23 i+32,7\right) .
\end{gathered}
$$

As a result of observations for the state of the metal structures of the rear axles rear suspension using tools and methods of visual control and extensometry, which were carried out at Kuzbass open pits (Kedrovskiy, Bachatskiy, Tomusinskiy) in the period of 2016 2017 , zones of increased formation of longitudinal defects, located in the places of attachment with frame, on the case and air chest, were determined. The most dangerous and progressive were cracks formed on the rear axle case. Based on this, the critical crack length $l_{\mathrm{c}}$ was calculated as:

$$
l_{c}=0.9 l_{0}
$$

where $l_{0}$ - is diameter of the rear axle case, $\mathrm{m}$.

Therefore, the critical length of the longitudinal crack-like defect on the case of the rear axle of the BelAZ-7555 mining truck was assumed to be $l_{\mathrm{c}}^{55}=0.78 \mathrm{~m}$, for BelAZ-75131 and BelAZ-75600, respectively, $l_{\mathrm{c}}^{130}=1.287 \mathrm{~m}, l_{\mathrm{c}}^{320}=1.935 \mathrm{~m}$. Substituting the results in formulae (8), we have the dependences of the total destructive energy of the structural sections of the rear axle on the longitudinal slope of the route (Fig. 2):

$$
\begin{gathered}
\gamma^{55}=1.17 \times 10^{-5}\left(0,024 i^{2}-1,07 i+39,1\right) \\
\gamma^{130}=1.93 \times 10^{-5}\left(0,012 i^{2}-0,5 i+33,9\right) \\
\gamma^{320}=2.91 \times 10^{-5}\left(0,006 i^{2}-0,23 i+32,7\right) .
\end{gathered}
$$




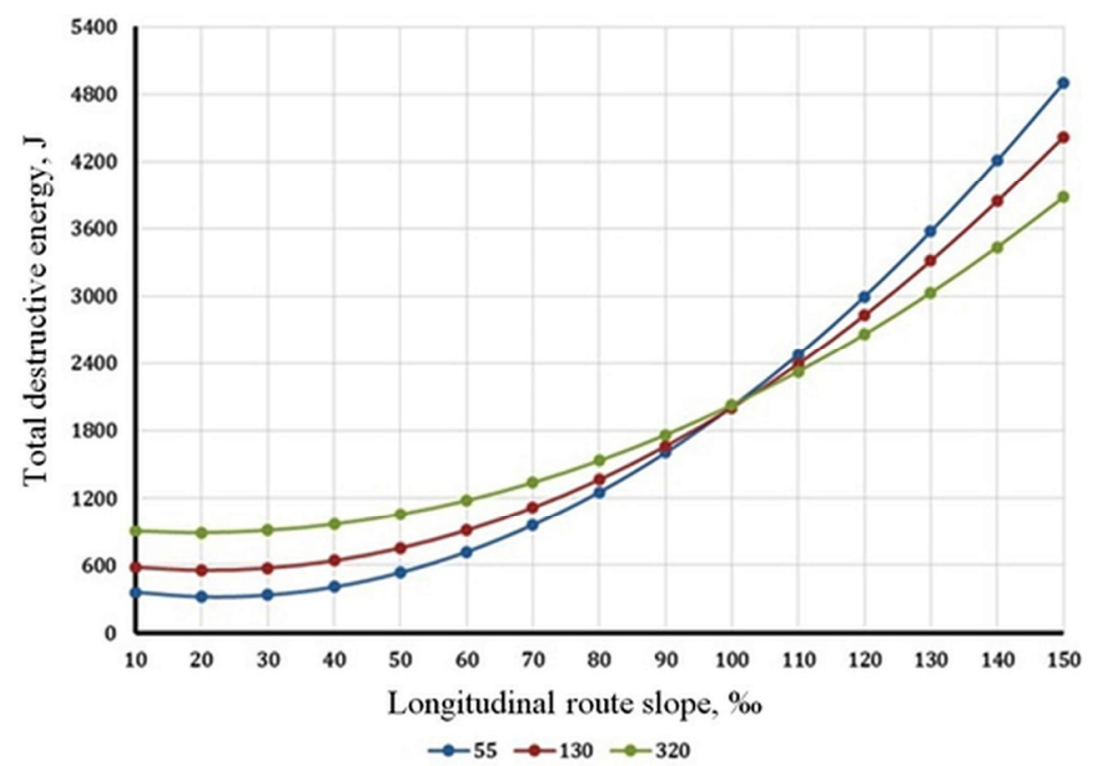

Fig. 2. Dependences of the total destructive energy of structural sections of mining trucks on the route slope.

\subsection{Results analysis}

Using the results obtained analytically, a diagram of dependences of the total destructive energy of the structural sections elements of the rear axles on the transportation energy of exploded rock mass of BelAZ dump trucks of various load capacities was built (Fig. 3).

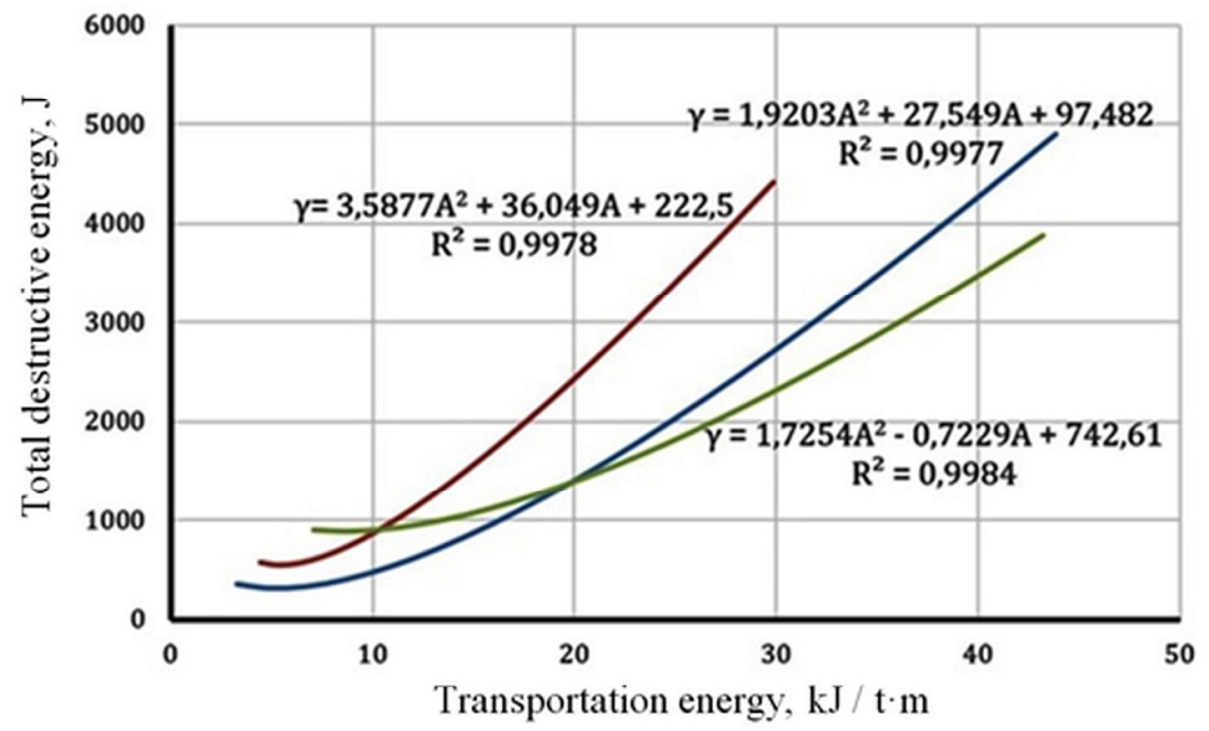

Fig. 3. Dependences of the total destructive energy on rock mass transportation energy. 
Figure 3 shows that the energy relationship of two nonsteady processes, destructive and transportation, is described by a polynomial law (the approximation coefficient is as close as possible to one in all three cases).

Earlier studies made it possible to establish the values of permissible longitudinal slopes of the route according to the criterion of durability of rear axle metal structures of a mining dump truck. The joint energy diagram was constructed on this basis; it allows obtaining the allowable values of the destructive and transportation energies for mining trucks of various carrying capacities (Fig. 4).

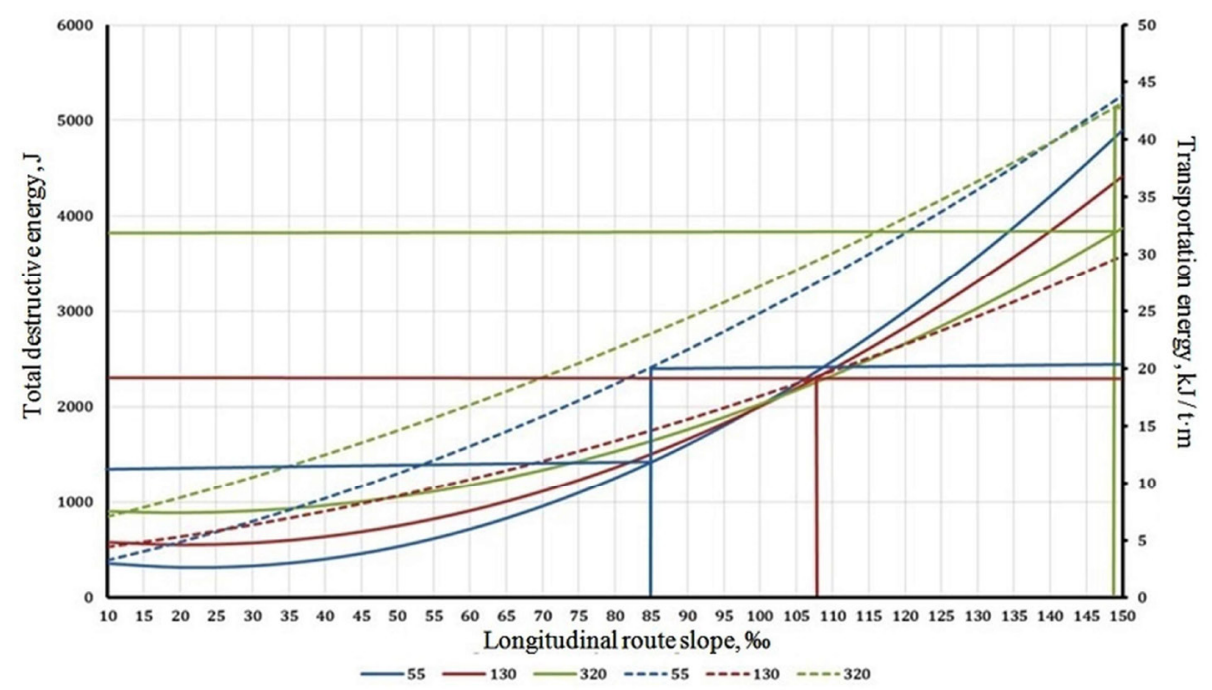

Fig. 4. Energy joint dependency diagram of the total destructive energy and transportation energy on the longitudinal route slope.

Figure 4 depicts in dash-dotted line the dependences of the energy of rock mass transportation by mining dump trucks with a carrying capacity of up to 55 tons (blue line), from 55 to 130 tons (red line) and from 130 to 320 tons (green line). Continuous lines show the influence of the route slope on the total destructive energy for trucks of the same carrying capacity. The vertical segments correspond to the permissible route slopes for heavy dump trucks of a certain group (the colour is the same).

The obtained results of the allowable energies were summarized in table 1.

Table 1. Permissible values of the destructive and transportation energies.

\begin{tabular}{|c|c|c|c|}
\hline Dump truck group & Route slope, \%o & $\begin{array}{c}\text { Total destruc- } \\
\text { tive energy, kJ }\end{array}$ & $\begin{array}{c}\text { Transportation } \\
\text { energy, kJ /tm }\end{array}$ \\
\hline Up to $55 \mathrm{t}$ & 85 & 1422 & 20 \\
\hline From 55 to $130 \mathrm{t}$ & 108 & 2313 & 19 \\
\hline From 130 to $320 \mathrm{t}$ & 149 & 3831 & 43 \\
\hline
\end{tabular}

Table 1 shows the maximum allowable values of slopes and energies for dump trucks of various carrying capacities. In case of exceeding the obtained energy values for transportation of exploded rock mass at given slope angles of the route, it is necessary to carry out diagnostic measures on the condition of the structural sections of a mining dump truck. 


\section{Conclusion}

Continuous monitoring of the destructive energy of the structural sections of mining dump trucks is complex and costly process, the implementation of which is significantly difficult in work environment.

Analysis of the change in the transportation energy of exploded rock mass by heavy dump trucks requires constant monitoring of the operating conditions of mining equipment, which today is carried out at all mining enterprises through GPS navigation and appropriate software.

The obtained energy dependences of two nonsteady processes, destructive and transportation, allow solving engineering and practical problems without significant downtime of open pit vehicles, labour and financial costs, and it helps to preserve and increase the resource of dump trucks structural sections.

\section{References}

1. I. A. Panachev, I. V. Kuznetsov, Journal of Mining Science, 51, 267, (2015)

2. B. Fan, Y. Yuan, International Journal of Mining Science and Technology, 26, 653 (2016)

3. I. A. Panachev, G. V. Shirokolobov, I. V. Kuznetsov, A. G. Shirokolobova, The 8th Russian-Chinese Symposium. Coal in the 21st Century: Mining, Processing and Safety, 1 (2016)

4. A. Soofastaei, S. M. Aminossadati, M. S. Kizil, P. Knights, International Journal of Mining Science and Technology, 26, 745 (2016)

5. I. V. Sokolov, A. A. Smirnov, Yu. G. Antipin, K. V. Baranovskii, Journal of Mining Science, 52, 121 (2016)

6. V. A. Solomennikov, V. I. Cheskidov, Journal of Mining Science, 51, 1213 (2015)

7. G. M. Dubov, D. S. Trukhmanov, S. A. Nokhrin, A. N. Sergel, MATEC Web of Conferences 297, 03002 (2019)

8. Ch. Zhang, I. Canbulat, F. Tahmasebinia, B. Hebblewhite, International Journal of Mining Science and Technology, 27, 43 (2017)

9. F. Xiao, G.Liu, Z. Zhang, Zh. Shen, F. Zhang, Y. Wang, International Journal of Mining Science and Technology, 26, 981 (2016)

10. J. Jiang, Q. Liu, J. Xu, International Journal of Mining Science and Technology, 26, 1003 (2016)

11. J. W. Puller, K. W. Mills, R. G. Jeffrey, R. J. Walker, International Journal of Mining Science and Technology, 26, 103 (2016)

12. G.M. Dubov, D. S. Trukhmanov, I. V. Kuznetsov, S. A. Nokhrin, A.N. Sergel, E3S Web Conf., 105, 03019 (2019)

13. S. A. Bornyakov, D. V. Salko, Journal of Mining Science, 52, 338 (2016)

14. G. M. Dubov, D. S. Trukhmanov, I. V. Kuznetsov, S. A. Nokhrin, A.N. Sergel, E3S Web Conf., 105, 03018 (2019)

15. S. S. Azikhanov, A. R. Bogomolov, G. M. Dubov, S. A. Nokhrin, MATEC Web Conf., 297, 03001 (2019) 